\title{
Youth's Responses to Peer Provocation: Links to Symptoms of Anxiety and Depression
}

\author{
Melanie A. Dirks • Teresa A. Treat • V. Robin Weersing
}

Published online: 30 January 2014

(C) Springer Science+Business Media New York 2014

\begin{abstract}
Youth experiencing anxiety and depression are more likely to be targeted aggressively by peers, making it critical that we understand how they respond to these challenging interpersonal situations. We addressed this issue by recruiting a school-based sample of lower-income youth $(N=327)$ in grades 6, 7, and 8 ( $M$ age $=13.10, S D=0.99)$ to complete a multiple-choice measure asking them to select responses to 11 scenarios describing physical, relational, and verbal provocation by a peer. We found that increasing anxiety was negatively associated with endorsement of aggressive behaviors, whereas greater levels of depressive symptoms were linked to higher rates of aggressive responding, and, for girls, decreased endorsement of assertive strategies. Implications for understanding and intervening on social competence and psychopathology are discussed.
\end{abstract}

Keywords Anxiety $\cdot$ Depression $\cdot$ Social skills $\cdot$ Peer provocation

Most children are targeted aggressively by peers at least some times (Card and Hodges 2008), and how they respond in these situations is critical, as ineffective strategies can escalate the harassment (e.g., Kochenderfer and Ladd 1997). Much research has focused on how youth with externalizing

M. A. Dirks ( $\triangle)$

Department of Psychology, Stewart Biological Sciences, McGill

University, W7/3J, 1205 Dr. Penfield Avenue, Montreal,

Quebec H3A1B1, Canada

e-mail: melanie.dirks@mcgill.ca

T. A. Treat

University of Iowa, Iowa, IA, USA

V. R. Weersing

San Diego State University/University of California at San Diego,

San Diego, CA, USA difficulties respond when provoked by peers (e.g., Dodge et al. 2002; Hughes et al. 2004). Anxiety and depression are also associated with increased rates of peer victimization (see Hawker and Boulton 2000), making it important to understand how youth experiencing internalizing symptoms manage peer aggression. In this study, we examined the associations between internalizing symptoms and youth responses to peer provocation, focusing on aggression occurring at the hands of a friend. Victimization occurs within friendship (Craig et al. 2007), and these experiences predict increased internalizing symptoms (e.g., Crick and Nelson 2002). Very little work, however, has investigated how children respond in these situations (Waasdorp et al. 2010).

\section{Social Difficulties and Internalizing Symptoms}

Both depression and anxiety are associated with marked social-skill deficits (Erath et al. 2007; Greco and Morris 2005; Spence and Liddle 1990). Compared to their typically developing peers, anxious youth are perceived to be less socially effective, assertive, prosocial, and friendly, as well as more awkward (Alfano et al. 2006; Gazelle et al. 2005; Inderbitzen-Nolan et al. 2007; see Cartwright-Hatton et al. 2005 for exception). Depression, on the other hand, is associated with higher levels of hostile and aggressive behavior (Altmann and Gotlib 1988; Bell-Dolan et al. 1993). A large body of literature has linked children's interpersonal behavior to key outcomes in the peer group (Ladd 1999), suggesting it is likely that these social-skill difficulties are contributing to the elevated rates of peer rejection and the lower-quality friendships experienced by youth with anxiety and depression (Bagwell and Schmidt 2011; Kingery et al. 2010; McDougall et al. 2001). For this reason, interpersonal behavior should be a central target for clinicians. 
There is increasing recognition of the clinical utility of assessing social behaviors with respect to key social situations (Dirks et al. 2012). Research has demonstrated that even youth experiencing significant psychopathology demonstrate problematic interpersonal behaviors in some situations, but not others (Wright et al. 1999). Moreover, the competence of any given behavioral strategy will vary as a function of the antecedent situation: assertiveness may be effective when one's rights are transgressed (Hopmeyer and Asher 1997), but work less well in a minor conflict (Rose and Asher 1999). To intervene efficiently and effectively, we must understand how youth are responding to specific, important, social situations.

One type of situation that will likely prove challenging for youth experiencing internalizing symptoms is peer provocation. Assertive responses (e.g., telling the person to stop) are likely to be an effective strategy in these circumstances: Both youth and teachers think assertive strategies will work reasonably well (Craig et al. 2007; Dirks et al. 2010), observational work has suggested that they de-escalate the immediate situation (Mahady Wilton et al. 2000), and use of assertion is associated with greater peer acceptance (Hopmeyer and Asher 1997). Internalizing symptoms are associated with socialcognitive biases that may decrease selection of these strategies, including tendencies to blame oneself in response to aversive events with peers (e.g., Prinstein et al. 2005; Quiggle et al. 1992), to perceive threat in social situations (Muris et al. 2000a, b), and to have less confidence in one's ability to carry out these responses (Daleiden and Vasey 1997; Quiggle et al. 1992). Moreover, youth experiencing depression and anxiety may have difficulty regulating the pronounced negative affect that often results from being targeted aggressively (Garber et al. 1995; Kochenderfer-Ladd 2004; Paquette and Underwood 1999; Suveg and Zeman 2004; Zeman et al. 2002), which may make it harder to mount a skillful response (Eisenberg et al. 1993; Hubbard and Coie 1994). Unfortunately, negative experiences with peers can increase emotion-regulation difficulties (McLaughlin et al. 2009), as well as the maladaptive social-cognitive patterns described previously (Dodge et al. 2003). Responding ineffectively to peer aggression, in turn, can exacerbate victimization (e.g., Elledge et al. 2010; Kochenderfer and Ladd 1997). As such, youth experiencing anxiety and depression may end up trapped in an escalating cycle of victimization and problematic responding.

Helping these youth learn to respond effectively during episodes of peer aggression may improve their functioning in the peer group, which could ameliorate symptomatology (Hodges et al. 1999; Hodges and Perry 1999). Little work has examined the associations between anxiety and depression and youth's management of peer provocation, although previous research has mapped out the links between internalizing symptoms and responding to challenging situations, more globally. This work has shown that anxiety and depression are associated with decreased endorsement of assertive strategies (Bell-Dolan 1995; Kennedy et al. 1989; Quiggle et al. 1992; Rudolph et al. 1994; Spence et al. 1999). Depression has also been linked to greater levels of aggressive responding, whereas anxiety is associated with lower reported use of aggression (Rudolph et al. 1994). Children identified as socially withdrawn, which can be a feature of both anxiety and depression, report greater use of avoidant strategies in challenging interpersonal scenarios (Burgess et al. 2006; Wichmann et al. 2004). However, a number of studies have not demonstrated associations between reported use of avoidant strategies and either anxiety or depression (Quiggle et al. 1992; Rudolph et al. 1994), suggesting these strategies may only be used by a subset of youth experiencing these symptoms.

\section{Current Work}

The current study builds on this work in several ways. First, we focused specifically on youth's management of peer provocation. Provocation is a class of situations likely to produce more aggressive responding (Wright et al. 1999), and less avoidant responding, particularly when the aggressor is a friend (Dirks et al. 2007b). As such, it is critical to examine youth management of this task directly, rather than extrapolating from other types of situations or more generalized behavioral assessments. To assess youth's reported responses to peer aggression, we used a measure, the Peer Provocation Inventory - Multiple-Choice (PPI-MC), that consists of scenarios describing physical, relational, and verbal aggression by a peer, each paired with a comprehensive set of nine responses based on actual strategies generated by youth (Dirks et al. 2007b.). Previously, we found that the threefactor structure used in previous studies of interpersonal behavior among youth (e.g., Deluty 1979; Quiggle et al. 1992; Rudolph et al. 1994)-aggression, avoidance, and assertion-fit youth responses on the PPI-MC (Dirks et al. 2011).

Second, we examined associations between this empirically based taxonomy of youth behavior and symptoms of anxiety and depression in a sample of early adolescents. Previous studies assessing the links between internalizing symptoms and interpersonal behavior have often focused on children younger than 12 years (e.g., Kennedy et al. 1989; Quiggle et al. 1992; Rudolph et al. 1994). Rates of depression rise sharply between 12 and 14 years of age, particularly for girls (Hankin et al. 1998), making it important that we understand the behavioral correlates of internalizing symptoms during this developmental stage. Moreover, the social strategies children utilize are likely to change with age, making it difficult to generalize to this age group from younger samples. In particular, aggressive retaliation becomes a more frequent response to peer aggression as youth get older (Camodeca and Goossens 
2005; Craig et al. 2007; Feldman and Dodge 1987). There is also some evidence that avoidant strategies, such as ignoring the person or saying nothing, are used more often by older youth (Craig et al. 2007; Underwood et al. 1999; but see Feldman and Dodge 1987), but telling an adult, which can also be considered a form of avoidance because the aggressor is not being confronted directly, becomes less common with age (Newman et al. 2001). Clear associations between age and use of assertive strategies have not emerged (e.g., Craig et al. 2007; Feldman and Dodge 1987; Kochenderfer-Ladd 2004).

Finally, in addition to being older, our sample was ethnically diverse and primarily lower-income. Lower-income youth are at greater risk for internalizing symptoms (e.g., Xue et al. 2005) and victimization (e.g., Dhami et al. 2005; Hanish and Guerra 2000). Moreover, several features of lower-income environments, including greater physical aggression in schools (e.g., Guerra et al. 1995) and increased neighborhood violence (e.g., Schwab-Stone et al. 1995), may moderate the associations between internalizing symptoms and interpersonal behavior, making it important, both clinically and theoretically, to examine these linkages in lowerincome samples.

Hypotheses Based on previous work we expected that greater levels of depression would be associated with increased selection of aggressive responses and decreased endorsement of assertion (e.g., Quiggle et al. 1992; Rudolph et al. 1994). Given that girls experience higher levels of depression than boys during early adolescence, we expected that there might be a significant interaction between gender and depression such that these associations are stronger for girls. We anticipated that increasing anxiety would predict lower endorsement of aggressive strategies (Rudolph et al. 1994). Some work suggests that anxiety may also be linked to decreased assertiveness (Bell-Dolan 1995; Spence et al. 1999); however, other studies have found that the association between anxiety and assertiveness is not significant, after accounting for depressive symptoms (Rudolph et al. 1994; Kennedy et al. 1989). We did not expect to find an association between either anxiety or depression and endorsement of avoidant responses given that previous work has not reliably demonstrated this relationship (Quiggle et al. 1992; Rudolph et al. 1994).

\section{Method}

\section{Participants}

Participants were youth in grades 6,7 , and $8(M$ age $=13.10$, $S D=0.99)$ attending a middle school in the northeastern United States. The average family income of students in this school was $\$ 18,404$, and $62 \%$ of students received free or reduced-cost lunch. Parents of all enrolled students were asked to provide written consent. Parents who did not return consent forms were contacted by telephone to obtain consent. Consent was obtained for 749 of 884 youth (85\%). Of the available participants, 327 students (37\%) completed the PPI$\mathrm{MC}$, which was not a focus of the primary study and was included last in the battery. This placement likely contributed to completion rates, as fatigue and time constraints may lead a number of participants to "drop out" while completing a measurement battery. Rates of completion were similar for questionnaires administered immediately prior to the PPI-MC. Demographic characteristics are presented in Table 1.

\section{Measures}

The Peer Provocation Inventory-Multiple-Choice (PPI-MC; Dirks et al. 2011) is a pen-and-paper measure that asks youth

Table 1 Descriptive statistics for measured variables

\begin{tabular}{|c|c|c|c|c|c|}
\hline Variable & $M$ & $S D$ & Range & $n$ & $\%$ of sample \\
\hline \multicolumn{6}{|l|}{ Demographic characteristics } \\
\hline Male & - & - & - & 148 & $45 \%$ \\
\hline Grade 6 & - & - & - & 117 & $36 \%$ \\
\hline Grade 7 & - & - & - & 100 & $31 \%$ \\
\hline Grade 8 & - & - & - & 110 & $34 \%$ \\
\hline Non-Hispanic White & - & - & - & 49 & $15 \%$ \\
\hline Hispanic & - & - & - & 153 & $47 \%$ \\
\hline African-American & - & - & - & 33 & $10 \%$ \\
\hline Other Ethnicity & - & - & - & 92 & $28 \%$ \\
\hline \multicolumn{6}{|l|}{ Psychopathology } \\
\hline CDI Raw Score & 9.78 & 7.55 & $0-39$ & - & - \\
\hline CDI T-Score & 49.20 & 11.09 & $34-97$ & - & - \\
\hline MASC Raw Score & 34.91 & 17.13 & $0-82$ & - & - \\
\hline MASC T-Score & 45.87 & 11.55 & $25-79$ & - & - \\
\hline \multicolumn{6}{|l|}{ Response to peer provocation } \\
\hline Physical aggression & 2.82 & 2.85 & $0-11$ & - & - \\
\hline Verbal aggression & 2.80 & 2.44 & $0-10$ & - & - \\
\hline $\begin{array}{l}\text { Ending relationship with } \\
\text { aggressor }\end{array}$ & 1.47 & 1.86 & $0-10$ & - & - \\
\hline $\begin{array}{l}\text { Damaging aggressor's } \\
\text { relationship with others }\end{array}$ & 1.46 & 1.54 & $0-8$ & - & - \\
\hline Doing nothing & 0.87 & 1.51 & $0-9$ & - & - \\
\hline Seeking explanation & 1.82 & 2.06 & $0-10$ & - & - \\
\hline Telling adult & 0.75 & 1.37 & $0-9$ & - & - \\
\hline $\begin{array}{l}\text { Stating provocation } \\
\text { crossed limits }\end{array}$ & 2.59 & 2.45 & $0-10$ & - & - \\
\hline $\begin{array}{l}\text { Seeking explanation+ } \\
\text { verbal aggression }\end{array}$ & 2.07 & 2.26 & $0-11$ & - & - \\
\hline
\end{tabular}

CDI Children's Depression Inventory, MASC Multidimensional Anxiety Scale for Children. Scores for response to provocation variables represent the mean number of situations (out of 11) in which a given response was endorsed 
how they would respond to 11 scenarios describing physical, relational, and verbal provocation by a peer. On this version of the PPI-MC, the aggressor was described as a "good friend." Children's responses often change as a function of aggressor identity (Burgess et al. 2006; Dirks et al. 2007b), necessitating that the antagonist be identified. Here we focused on conflict within friendships in light of the importance of maintaining these relationships for children's well-being, particularly for youth with depression (Bagwell and Schmidt 2011).

Each vignette is paired with nine possible responses, based on actual strategies generated by youth (Dirks et al. 2007b). In this earlier investigation, responses were coded reliably into eight descriptive categories, which captured $80 \%$ of the strategies: physical aggression, verbal aggression, ending one's relationship with the aggressor, damaging the aggressor's relationship with others, doing nothing, seeking an explanation, telling an adult, and stating that the provocation crossed limits. Scenarios are paired with one response from each category, and an additional response combining verbal aggression and seeking an explanation (e.g., say "what's wrong with you?"), which was included because many children generated responses involving both of these strategies. Participants were instructed to indicate everything they would "actually say or do." Selecting multiple strategies was permitted, as our previous work suggested that many youth gave responses involving more than one category (Dirks et al. 2007b). Children receive a score out of 11 for each response type (e.g., a physicalaggression score of two indicates that a child endorsed the physically aggressive response in two situations). There is evidence for the test-retest reliability of this measure (Dirks et al. 2013a), as well as its convergent validity. For example, we have found that youth's greater endorsement of aggressive responses is associated with higher ratings of conduct problems and lower ratings of social skill by parents, whereas the opposite pattern is observed for youth's reported use of assertive strategies (Dirks et al. 2013b).

The Multidimensional Anxiety Scale for Children (MASC; March 1997) is a widely used 39-item measure assessing physical symptoms of anxiety, social anxiety, harm avoidance, and separation anxiety. Each item asks participants to rate how true a statement is of them on a four-point scale $(0=$ never true about me, 1=rarely true about me, 2=sometimes true about $m e$, and $3=$ often true about me). The MASC has high internal consistency and test-retest reliability, and its convergent and discriminant validity have been demonstrated (Muris et al. 2002). In the current sample Cronbach's alpha was 0.95.

The Children's Depression Inventory (CDI; Kovacs 1992) is a 27-item measure assessing five features of youth depression: negative mood, interpersonal difficulties, ineffectiveness, anhedonia, and negative self-esteem. Each item presents three statements representing different levels of a depressive symptom. When scoring, these statements are converted into a numerical score from 0 (symptom absent) to 2 (symptom severe). The item concerning suicidal ideation was omitted at the request of the school board. The CDI has been shown to have good psychometric properties, including test-retest reliability and convergent validity (Kovacs 1992). In the current sample Cronbach's alpha was 0.88 .

\section{Procedure}

All procedures were approved by the Institutional Review Board. Measures were administered as part of a battery designed to evaluate a social-emotional learning curriculum. Participants in this study were in a control school that did not receive the intervention.

Data were collected during one school period (approximately $1.5 \mathrm{~h}$ ) using pen-and-paper measures, and all students in the classroom received a mechanical pencil as a token of our appreciation. Several research assistants were present in each class to answer questions and assist any students having difficulty reading or understanding the questions. Classroom teachers remained in the room but did not interact with students concerning the questionnaires. Participants began by completing a brief demographic measure in which they identified their gender, birthday, school grade, and race/ethnicity. Measures were administered in both the fall and spring. We examined the factor-structure of the PPI-MC using the data collected in the fall (Dirks et al. 2011). Subsequent to this data collection, we made minor modifications to this measure; thus, the analyses examining the links between psychopathology and youth responses to peer provocation were conducted on the data collected in the spring ( $68 \%$ of participants also completed the PPI-MC in the fall).

\section{Analyses and Results}

\section{Data Screening}

Given the high percentage of participants who did not complete the PPI-MC, chi-square analyses were conducted to assess if completion was associated with gender, grade, and ethnicity. These analyses revealed that girls were more likely to complete the questionnaire, $\chi 2(1)=6.53, p<0.05$. In addition, ethnicity was associated significantly with completion, $\chi 2(3)=23.07, p<0.01$. The pattern of results suggested that non-Hispanic white participants $(60 \%)$ were more likely to complete the measures than African-American participants (52\%) and Hispanic participants (40\%). Possible implications of these differences are examined in the discussion section. Independent samples t-tests indicated that participants who did not complete the measure did not differ from those who did on either the CDI or the MASC.

Inspection of the data revealed that a small number of participants endorsed a large number of responses on the 
PPI-MC that likely did not reflect strategies they would actually use. These cases $(4 \%)$ were removed. Preliminary data screening also indicated that the distributions of several of the variables demonstrated significant positive skew (e.g., physical aggression). No transformation resulted in sufficiently normal distributions; thus, in all analyses, which were conducted using AMOS 18.0, standard errors were constructed using bootstrap techniques. Table 1 reports descriptive statistics for all measured variables. Zero-order correlations among all variables are presented in an Appendix.

Associations Between Internalizing Symptoms

and Responses to Peer Provocation

We began the current analyses by ensuring that the previously reported factor structure of the PPI-MC (Dirks et al. 2011) provided adequate fit to these data. $\mathrm{Hu}$ and Bentler (1999) suggest that CFIs exceeding 0.95 and RMSEAs with lowerbound confidence intervals (CIs) lower than 0.06 reflect adequate model fit. Using these criteria, the established threefactor model-aggression, avoidance, and assertion-provided adequate fit to the data, $\mathrm{CFI}=1.00$, RMSEA $=0.029(90 \% \mathrm{CI}=$ $0.000-0.061$ ). In addition, the Bollen-Stine bootstrap test, a modified version of the chi-square test used with bootstrapped standard errors, was also non-significant, $p=0.39$, suggesting good fit. Factor loadings for this model are presented in Fig. 1. Two of the loadings were not significant: stating that the provocation crossed limits on aggression, $\beta=0.05$, and verbal aggression on assertion, $\beta=0.15$. In the previous model, these loadings were significant, but also small in magnitude: $\beta \mathbf{s}=$ $0.18,0.23$, respectively. Given that the primary factor loadings all replicated, these small differences are likely the result of random variability.

Next, we created a structural model incorporating the predictors of interest. Scores on the MASC and the CDI were the primary independent variables. Gender and its bivariate interactions with CDI and MASC scores were also entered in the model, along with the CDI $x$ MASC interaction. Grade and ethnicity were entered as covariates. Ethnicity was dummy coded into three variables comparing non-Hispanic white participants to Hispanic participants, African-American participants, and participants of other ethnicities. The model included covariance terms among all predictor variables and the interaction terms listed above. The structural model also provided adequate fit to the data, $\mathrm{CFI}=0.98$, RMSEA $=0.045$ (90\% CI $=0.030-0.059)$. Associations among latent factors and predictors of interest are presented in Table 2. Given the number of comparisons, alpha was set at a more conservative 0.01 . Increasing depression was associated with greater endorsement of aggressive strategies, whereas greater levels of anxiety predicted less aggressive responding. In addition, there was a significant interaction between gender and depression for assertiveness.
To unpack this interaction, follow-up analyses were conducted following the strategy outlined by Holmbeck (2002). Two gender variables were created: In the first, males were coded as 0 and females were coded as 1 and in the second males were coded as -1 and females were coded as 0 . Two interaction terms were created by multiplying each gender variable by CDI scores. Then, two analyses were run, each including CDI score, gender, and the respective interaction term. These revealed a significant association between increasing depression and lower assertiveness for girls, $\beta=-0.29$, $p<0.01$; but not boys, $\beta=0.03, p>0.05$.

\section{Discussion}

The goal of this study was to contribute to our understanding of the interpersonal difficulties associated with internalizing symptoms by examining the relationship between both depression and anxiety and youth responses to peer provocation, a class of situations that is commonly occurring, difficult to manage, and associated with negative consequences if handled poorly. Results suggested that increased depressive symptoms were associated with a profile of responses to peer provocation that may exacerbate victimization. As expected, greater dysphoria was associated with increased endorsement of aggressive responses, strategies that have been linked to continued and increased harassment (Elledge et al. 2010; Kochenderfer-Ladd 2004; Mahady Wilton et al. 2000). Moreover, for girls, but not for boys, increasing depression was associated with decreased assertive responding, the strategy most likely to be perceived as socially competent (Dirks et al. 2010; Hopmeyer and Asher 1997; Mahady Wilton et al. 2000). This interaction may be due, in part, to the fact that girls, in general, are more likely to endorse assertive responses than boys, a finding that mirrors the broader literature (Rose and Rudolph 2006). Taken together, these results suggest that depression may be associated with a more problematic profile of interpersonal behavior among girls. This pattern is consistent with previous work demonstrating that the associations between depression and generation of interpersonal stress are stronger for girls than boys (Rudolph et al. 2000).

As we hypothesized, anxiety was associated with a different profile of interpersonal behaviors. Consistent with earlier research (Rudolph et al. 1994), we found that increasing anxiety was associated with decreasing levels of aggressive responding. As reviewed previously, anxiety and depression are associated with similar cognitive biases, yet appear to have distinct behavioral manifestations. One reason for this divergence may be the nature of the symptomatology. One feature of anxiety assessed in the current study is harm avoidance, which includes obeying rules and trying to do the right thing (March 1997). Youth experiencing high levels of harm avoidance may be less likely to engage in aggressive behaviors, which are generally not sanctioned by authority figures and 
Fig. 1 Measurement model linking behavioral strategies used in response to peer provocation to the latent factors of aggression, avoidance, and assertion. ${ }^{*} p<0.05 .{ }^{* *} p<0.01$

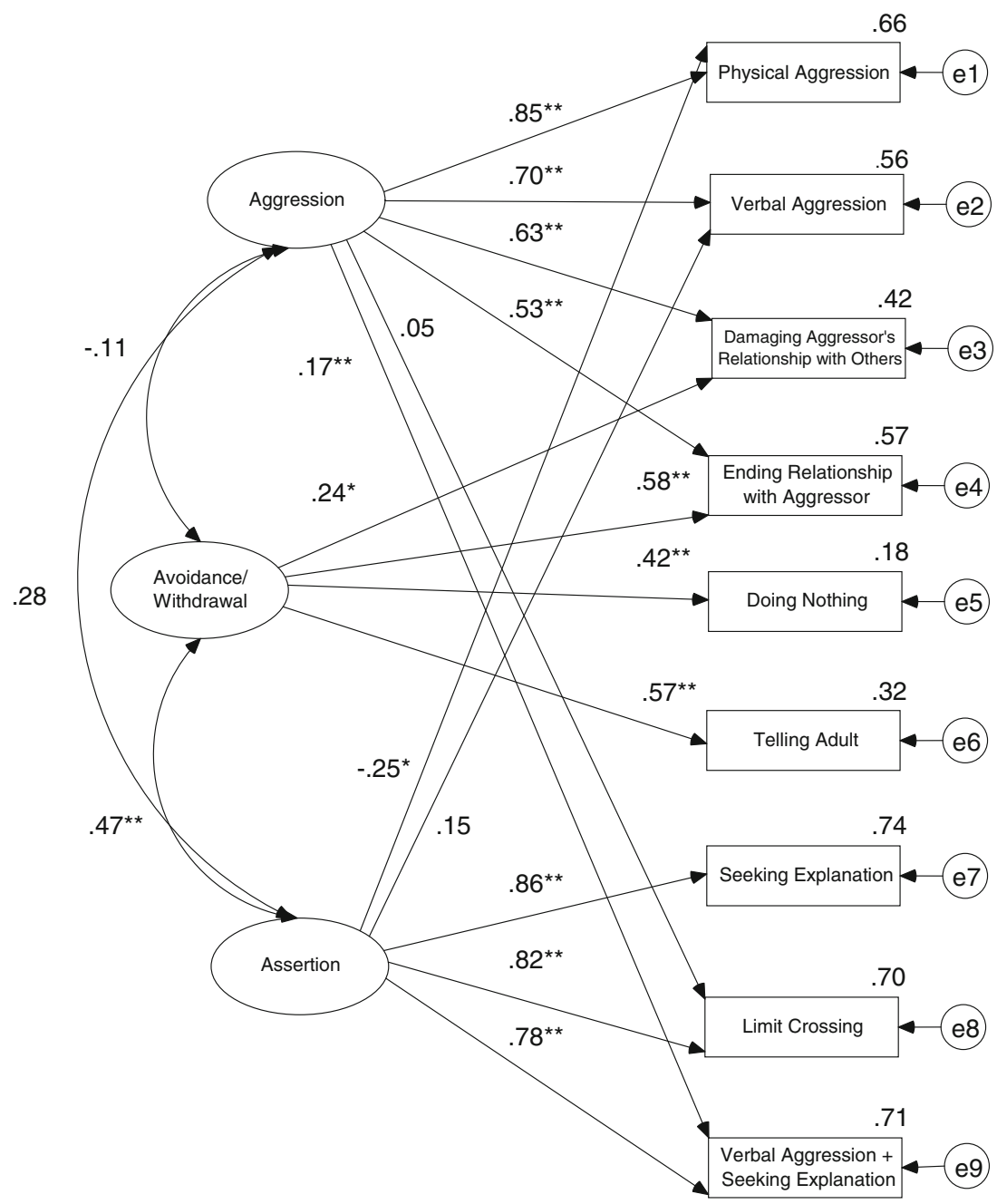

would involve breaking rules, particularly at school, where the vignettes take place. Similarly, social anxiety involves fear of embarrassment and negative evaluation (Beidel et al. 1991). Youth experiencing these concerns may not want to engage in aggressive altercations which might draw attention to them.

Unlike depression, anxiety was not associated with endorsement of assertive responses. Previous work with clinical samples has suggested that social anxiety is associated with less assertive responding (Spence et al. 1999); however, in our community sample, only $10 \%$ of respondents exceeded the "much above average" cut points indicated by March (1997). Reduced assertiveness may only occur for youth demonstrating high levels of anxiety. Furthermore, it may be that the situations we examined did not press for reductions in assertiveness for children experiencing anxiety. Contending with an aggressor who is an unknown classmate, rather than a friend, may prove more challenging for these youth, and under these circumstances, anxiety might be associated with a decrease in assertive responding.

These results suggest that, in a community sample, anxiety may not be associated with as much difficulty responding to peer provocation as is depression: The interpersonal profile associated with increasing anxiety does not confer the same risk for future victimization as the one that accompanies rising depression. In fact, given that anxiety is associated with decreased levels of aggressive responding, strategies that are seen as incompetent by teachers, these symptoms might serve a protective function, at least from the vantage point of adults. It should be noted, however, that some children view aggressive responses to provocation as effective (Dirks et al. 2010). Thus, it is possible that not responding aggressively may actually be viewed as problematic by certain groups of peers.

We did not find an association between either depression or anxiety and avoidant responding, a pattern observed in other studies (Quiggle et al. 1992; Rudolph et al. 1994). The provocation situations we examined are associated with low levels of avoidant responding-telling an adult and doing nothing were the least chosen strategies, with only $8 \%$ and $9 \%$ of all responses in these categories, respectively-and these low frequencies may have attenuated the associations between internalizing symptoms and selection of avoidant strategies. 
Table 2 Standardized coefficients when predicting the latent factors aggression, avoidance, and assertion

\begin{tabular}{lccc}
\hline & Aggression & Avoidance & Assertion \\
\hline Anxiety & $-0.37^{*}$ & 0.06 & 0.08 \\
Depression & $0.25^{*}$ & -0.03 & 0.04 \\
Anxiety x Depression & 0.10 & 0.01 & -0.01 \\
Anxiety x Gender & 0.19 & 0.03 & 0.04 \\
Depression x Gender & -0.19 & -0.06 & $-0.27^{*}$ \\
Gender & 0.05 & 0.13 & $0.20^{*}$ \\
Grade & -0.04 & -0.16 & -0.07 \\
Ethnicity & & & \\
$\quad$ Hispanic & 0.16 & 0.18 & 0.02 \\
African-American & 0.12 & -0.02 & -0.12 \\
Other Ethnicities & 0.16 & 0.05 & -0.06 \\
\hline
\end{tabular}

Gender dummy coded so that females $=1$. Ethnicity variables were dummy coded so that the identified ethnicity $=1$, all other ethnicities $=0$, with non-Hispanic White as the reference category

Coefficients were calculated in a structural model that included covariance terms among all predictor variables, as well as the three latent factors $* p<0.01$

It is possible that anxiety and depression may be associated with increased withdrawal in other types of situations, such as approaching a group of classmates to join an activity.

It is important to note several limitations in the current study. First, a significant percentage of the available sample did not complete the measure and rates of completion were associated with gender and ethnicity, although not with anxiety and depression. One reason for the relatively high rate of non-completion is that our sample consisted primarily of lower-income youth. Lower SES is associated with increased behavioral difficulties (Tolan et al. 1997) and attending a school with elevated rates of absenteeism, suspensions, and truancy (Peng and Lee 1993), factors that may increase the likelihood of not completing research questionnaires. Lower-SES youth, however, are at greater risk for psychological and social difficulties making it important that we conduct research with these samples. Furthermore, the fact that children experiencing behavioral difficulties are more likely not to complete research questionnaires suggests that our findings may reflect a conservative, rather than a liberal, bias. For example, the inclusion of more youth experiencing aggressive behavior problems may strengthen the significant association we found between depression and endorsement of aggressive responding.

All measures in this study were self-report, which is consistent with other studies examining the associations between internalizing symptoms and youth management of key interpersonal scenarios (e.g., Bell et al. 2009; Quiggle et al. 1992). Researchers likely rely on self-report to answer these types of questions because (a) self-report is often given precedence in the assessment of internalizing problems, and (b) it is difficult to obtain a situation-specific picture of interpersonal functioning using other methodologies. For example, naturalistic observations involve measuring youth responding to unstandardized social situations, limiting the inferences that can be drawn about associations among specific interpersonal contexts and behaviors, and lab-based observational procedures typically limit the investigator to one or two situations (Dirks et al. 2007a). Similarly, although peer nomination procedures can be used to obtain a general picture of behavior, it may be difficult for peers to report on children's responses to specific situations. There is evidence that children's reported responses to specific social situations are associated with others' reports of their behavior (e.g., Chung and Asher 1996; Deluty 1979; Wichmann et al. 2004), and that children's report of the strategies they use to manage key situations that occur in friendships is linked to the quality of those relationships (Rose and Asher 1999; 2004), suggesting that youth report is a valid index of their behavior. Use of one informant does, however, introduce the possibility of shared method variance, making it important to situate these findings within the broader context of work using a variety of methodologies to examine the associations between internalizing symptoms and social behavior.

Finally, measures of oppositional defiant disorder and conduct disorder were not included. It is therefore not possible for us to determine if the increase in aggression associated with depression is at least partially due to the presence of comorbid behavioral difficulties. Nonetheless, these data would still seem to provide further evidence for the specificity of the interpersonal dysfunction associated with depression, as compared to anxiety.

The current work contributes to our knowledge of the social difficulties of youth with anxiety and depression by examining how these syndromes relate to responses to peer provocation. Findings indicated that depression, in particular, was associated with response tendencies that may serve to escalate levels of victimization, suggesting that helping youth experiencing these symptoms learn to manage episodes of peer aggression more effectively may pay dividends for both social functioning and symptomatology. In general, more precise delineation of how both symptoms and severity of youth anxiety and depression are related to behavioral strategies in key interpersonal situations may help to improve the efficacy of social-skills programs targeting youth experiencing internalizing symptoms.

Conflict of Interest Melanie A. Dirks declares that there is no conflict of interest; Teresa A. Treat declares that there is no conflict of interest; V. Robin Weersing declares that there is no conflict of interest.

Experiment Participants All procedures were approved by the local Institutional Review Board. All parents provided informed consent and all children provided assent before taking part in the study. 


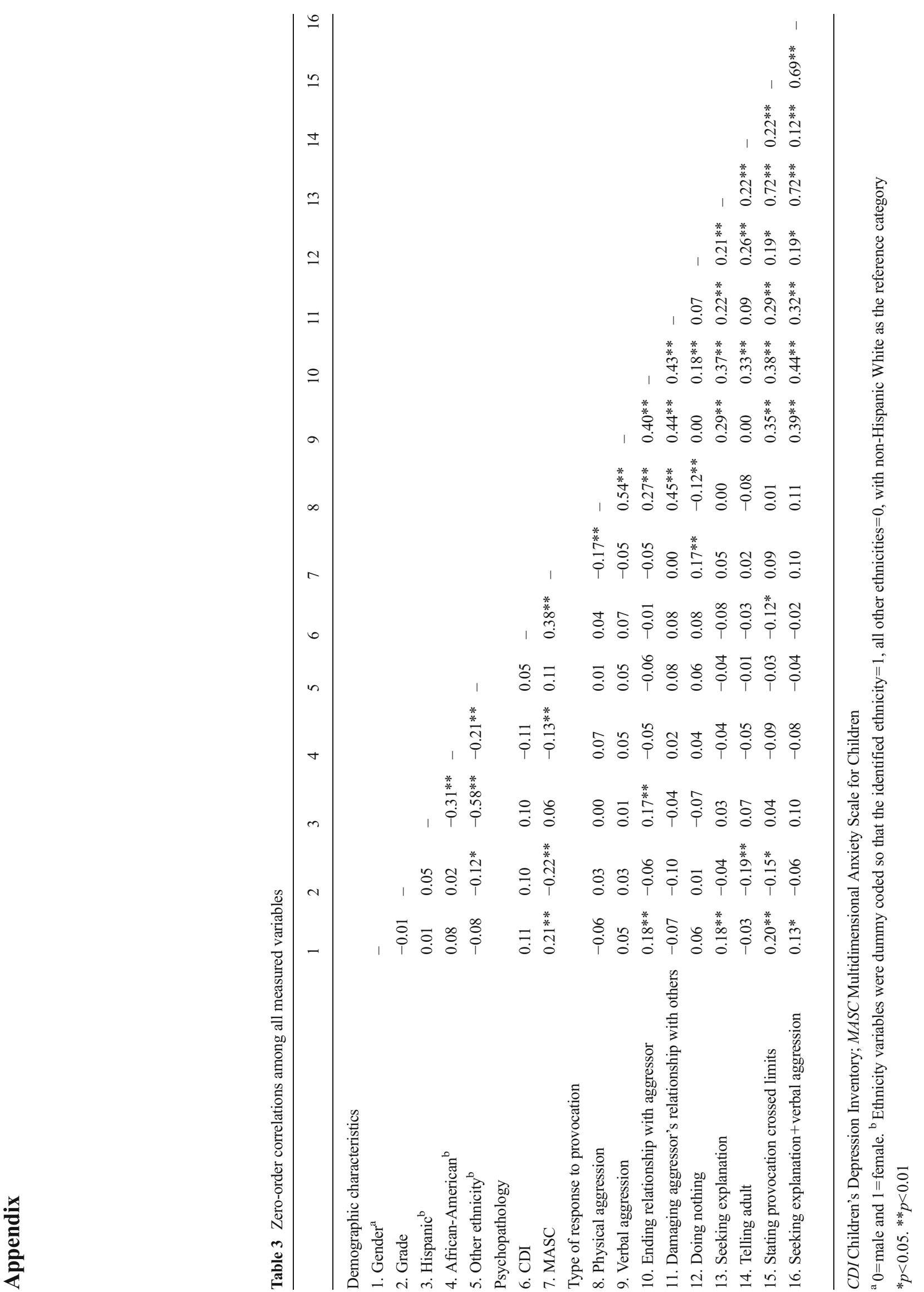




\section{References}

Alfano, C. A., Beidel, D. C., \& Turner, S. M. (2006). Cognitive correlates of social phobia among children and adolescents. Journal of Abnormal Child Psychology, 34, 189-201.

Altmann, E. O., \& Gotlib, I. H. (1988). The social behavior of depressed children: An observational study. Journal of Abnormal Child Psychology, 16, 29-44.

Bagwell, C. L., \& Schmidt, M. E. (2011). Friendships in childhood and adolescence. New York: Guilford.

Beidel, D. C., Christ, M. A., \& Long, P. J. (1991). Somatic complaints in anxious children. Journal of Abnormal Child Psychology, 19, 659670 .

Bell, D. J., Luebbe, A. M., Swenson, L. P., \& Allwood, M. A. (2009). The Children's Evaluation of Everyday Social Encounters Questionnaire: Comprehensive assessment of children's social information processing and its relation to internalizing problems. Journal of Clinical Child and Adolescent Psychology, 38, 705-720.

Bell-Dolan, D. J. (1995). Social cue interpretation of anxious children. Journal of Clinical Child Psychology, 24, 2-10.

Bell-Dolan, D. J., Reaven, N. M., \& Peterson, L. (1993). Depression and social functioning: A multidimensional study of the linkages. Journal of Clinical Child Psychology, 22, 306-315.

Burgess, K. B., Wojslawowicz, J. C., Rubin, K. H., Rose-Krasnor, L., \& Booth-LaForce, C. (2006). Social information processing and coping strategies of shy/withdrawn and aggressive children: Does friendship matter? Child Development, 77, 371-383.

Camodeca, M., \& Goossens, F. A. (2005). Children's opinions on effective strategies to cope with bullying: The importance of bullying role and perspective. Educational Research, 47, 93-105.

Card, N. A., \& Hodges, E. V. E. (2008). Peer victimization among schoolchildren: Correlations, causes, consequences, and considerations in assessment and intervention. School Psychology Quarterly, 23, 451-461.

Cartwright-Hatton, S., Tschernitz, N., \& Gomersall, H. (2005). Social anxiety in children: social skills deficit, or cognitive distortion? Behavior Research and Therapy, 43, 131-141.

Chung, T. Y., \& Asher, S. R. (1996). Children's goals and strategies in peer conflict situations. Merrill-Palmer Quarterly, 42, 125-147.

Craig, W., Pepler, D., \& Blais, J. (2007). Responding to bullying: What works? School Psychology International, 28, 465-477.

Crick, N. R., \& Nelson, D. A. (2002). Relational and physical victimization within friendships: Nobody told me there'd be friends like these. Journal of Abnormal Child Psychology, 30, 599-607.

Daleiden, E. L., \& Vasey, M. W. (1997). An information-processing perspective on childhood anxiety. Clinical Psychology Review, 17, 407-429.

Deluty, R. H. (1979). Children's Action Tendency Scale: A self-report measure of aggressiveness, assertiveness, and submissiveness in children. Journal of Consulting and Clinical Psychology, 47, 1061-1071.

Dhami, M. K., Hoglund, W. L., Leadbeater, B. J., \& Boone, E. M. (2005). Gender-linked risks for peer physical and relational victimization in the context of school-level poverty in first grade. Social Development, 14, 532-549.

Dirks, M. A., Cuttini, L. A., Mott, A. J., \& Henry, D. B. (2013a). Associations between children's reported responses to peer aggression and victimization are moderated by aggressiveness. Manuscript under review.

Dirks, M. A., De Los Reyes, A., Briggs-Gowan, M., Cella, D., \& Wakschlag, L. S. (2012). Embracing not erasing contextual variability in children's behavior-theory and utility in the selection and use of methods and informants in developmental psychopathology. Journal of Child Psychology and Psychiatry, 53, 558-574.
Dirks, M. A., Suor, J. H., Rusch, D., \& Frazier, S. L. (2013b). Children's responses to hypothetical provocation by peers: Coordination of assertive and aggressive strategies. Manuscript under review.

Dirks, M. A., Treat, T. A., \& Weersing, V. R. (2007a). Integrating theoretical, measurement, and intervention models of youth social competence. Clinical Psychology Review, 27, 327-347.

Dirks, M. A., Treat, T. A., \& Weersing, V. R. (2007b). The situation specificity of youth responses to peer provocation. Journal of Clinical Child and Adolescent Psychology, 36, 621-628.

Dirks, M. A., Treat, T. A., \& Weersing, V. R. (2010). The judge specificity of evaluations of youth social behavior: The case of peer provocation. Social Development, 19, 736-757.

Dirks, M. A., Treat, T. A., \& Weersing, V. R. (2011). The latent structure of youth responses to peer provocation. Journal of Psychopathology and Behavioral Assessment, 33, 58-68.

Dodge, K. A., Laird, R., Lochman, J. E., Zelli, A., \& the Conduct Problems Prevention Research Group. (2002). Multidimensional latent construct analysis of children's social information processing patterns: Correlations with aggressive behavior problems. Psychological Assessment, 14, 60-73.

Dodge, K. A., Lansford, J. E., Burks, V. S., Bates, J. E., Pettit, G. S., Fontaine, R., \& Price, J. M. (2003). Peer rejection and social information-processing factors in the development of aggressive behavior problems in children. Child Development, 74, 374-393.

Eisenberg, N., Fabes, R. A., Bernzweig, J., Karbon, M., Poulin, R., \& Hanish, L. (1993). The relations of emotionality and regulation to preschoolers' social skills and sociometric status. Child Development, 64, 1418-1438.

Elledge, L. C., Cavell, T. A., Ogle, N. T., Malcolm, K. T., Newgent, R. A., \& Faith, M. A. (2010). History of peer victimization and children's response to school bullying. School Psychology Quarterly, 25, 129 141.

Erath, S. A., Flanagan, K. S., \& Bierman, K. L. (2007). Social anxiety and peer relations in early adolescence: Behavioral and cognitive factors. Journal of Abnormal Child Psychology, 35, 405-416.

Feldman, E., \& Dodge, K. A. (1987). Social information processing and sociometric status: Sex, age, and situational effects. Journal of Abnormal Child Psychology, 15, 211-227.

Garber, J., Braafladt, N., \& Weiss, B. (1995). Affect regulation in depressed and nondepressed children and young adolescents. Development and Psychopathology, 7, 93-115.

Gazelle, H., Putallaz, M., Li, Y., Grimes, C. L., Kupersmidt, J. B., \& Coie, J. D. (2005). Anxious solitude across contexts: Girls' interactions with familiar and unfamiliar peers. Child Development, 76, 227 246.

Greco, L. A., \& Morris, T. L. (2005). Factors influencing the link between social anxiety and peer acceptance: Contributions of social skills and close friendships during middle childhood. Behavior Therapy, 36, 197-205.

Guerra, N. G., Huesmann, L. H., Tolan, P. H., Van Acker, R., \& Eron, L. D. (1995). Stressful events and individual beliefs as correlates of economic disadvantage and aggression among urban children. Journal of Consulting and Clinical Psychology, 63, 518-528.

Hanish, L. D., \& Guerra, N. G. (2000). Predictors of peer victimization among urban youth. Social Development, 9, 521-543.

Hankin, B. L., Abramson, L. Y., Moffit, T. E., Silva, P. A., McGee, R., \& Angell, K. E. (1998). Development of depression from preadolescence to young adulthood: Emerging gender differences in a 10-year longitudinal study. Journal of Abnormal Psychology, 107, 128-140.

Hawker, D. S. J., \& Boulton, M. J. (2000). Twenty years' research on peer victimization and psychosocial maladjustment: A meta-analytic review of cross-sectional studies. Journal of Child Psychology and Psychiatry, 41, 441-455.

Hodges, E. V. E., Boivin, M., Vitaro, F., \& Bukowski, W. M. (1999). The power of friendship: Protection against an escalating cycle of peer victimization. Developmental Psychology, 35, 94-101. 
Hodges, E. V. E., \& Perry, D. G. (1999). Personal and interpersonal antecedents and consequences of victimization by peers. Journal of Personality and Social Psychology, 76, 677-685.

Holmbeck, G. N. (2002). Post-hoc probing of significant moderational and mediational effects in studies of pediatric populations. Journal of Pediatric Psychology, 27, 87-96.

Hopmeyer, A., \& Asher, S. R. (1997). Children's responses to peer conflicts involving a rights infraction. Merrill-Palmer Quarterly, 43, 235-254.

Hu, L., \& Bentler, P. M. (1999). Cutoff criteria for fit indices in covariance structure analysis: Conventional criteria versus new alternatives. Structural Equation Modeling, 6, 1-55.

Hubbard, J. A., \& Coie, J. D. (1994). Emotional correlates of social competence in children's peer relationships. Merrill-Palmer Quarterly, 40, 1-20.

Hughes, J. N., Webster-Stratton, B., \& Cavell, T. A. (2004). Development and validation of a gender-balanced measure of aggression-relevant social cognition. Journal of Clinical Child and Adolescent Psychology, 33, 292-302.

Inderbitzen-Nolan, H. M., Anderson, E. R., \& Johnson, H. S. (2007). Subjective versus objective ratings following two analogue tasks: A comparison of socially phobic versus non-anxious adolescents. Journal of Anxiety Disorders, 21, 76-90.

Kennedy, E., Spence, S. H., \& Hensley, R. (1989). An examination of the relationship between childhood depression and social competence amongst primary school children. Journal of Child Psychology and Psychiatry, 30, 561-573.

Kingery, J. N., Erdley, C. A., Marshall, K. C., Whitaker, K. G., \& Reuter, T. R. (2010). Peer experiences of anxious and socially withdrawn youth: An integrative review of the developmental and clinical literature. Clinical Child and Family Psychology Review, 13, 91-128.

Kochenderfer, B. J., \& Ladd, G. W. (1997). Victimized children's responses to peers' aggression: Behaviors associated with reduced versus continued victimization. Development and Psychopathology, 9, 59-73.

Kochenderfer-Ladd, B. (2004). Peer victimization: The role of emotions in adaptive and maladaptive coping. Social Development, 13, 329349.

Kovacs, M. (1992). Children's Depression Inventory manual. North Tonawanda: Multi-Health Systems.

Ladd, G. W. (1999). Peer relationships and social competence during early and middle childhood. Annual Review of Psychology, 50, 333359.

Mahady Wilton, M. M., Craig, W. M., \& Pepler, D. J. (2000). Emotional regulation and display in classroom victims of bullying: Characteristic expressions of affect, coping styles and relevant contextual factors. Social Development, 9, 226-245.

March, J. S. (1997). Multidimensional Anxiety Scale for Children. North Tonawanda: Multi-Health Systems.

McDougall, P., Hymel, S., Vaillancourt, T., \& Mercer, L. (2001). The consequences of childhood peer rejection. In M. Leary (Ed.), Interpersonal rejection (pp. 213-250). New York: Oxford.

McLaughlin, K. A., Hatzenbuehler, M. L., \& Hilt, L. M. (2009). Emotion dysregulation as a mechanism linking peer victimization to internalizing symptoms in adolescents. Journal of Consulting and Clinical Psychology, 77, 894-904.

Muris, P., Kindt, M., Bogels, S., Merckelbach, H., Gadet, B., \& Moulaert, V. (2000a). Anxiety and threat perception abnormalities in normal children. Journal of Psychopathology and Behavioral Assessment, $22,183-199$

Muris, P., Luermans, J., Merckelbach, H., \& Mayer, B. (2000b). "Danger is lurking everywhere." The relation between anxiety and threat perception abnormalities in normal children. Journal of Behavior Therapy and Experimental Psychiatry, 31, 123-136.

Muris, P., Merckelbach, H., Ollendick, T., King, N., \& Bogie, N. (2002). Three traditional and three new childhood anxiety questionnaires:
Their reliability and validity in a normal adolescent sample. Behaviour Research and Therapy, 40, 753-772.

Newman, R. S., Murray, B., \& Lussier, C. (2001). Confrontation with aggressive peers at school: Students' reluctance to seek help from the teacher. Journal of Educational Psychology, 93, 398-410.

Paquette, J. A., \& Underwood, M. K. (1999). Gender differences in young adolescents' experiences of peer victimization: Social and physical aggression. Merrill-Palmer Quarterly, 45, 242-266.

Prinstein, M. J., Cheah, C. S., \& Guyer, A. E. (2005). Peer victimization, cue interpretation, and internalizing symptoms: Preliminary concurrent and longitudinal findings for children and adolescents. Journal of Clinical Child and Adolescent Psychology, 34, $11-24$.

Peng, S. S., \& Lee, R. M. (1993). Educational experience and needs of middle school students in poverty. Washington: National Center for Education Statistics, US Department of Education.

Quiggle, N. L., Garber, J., Panak, W. F., \& Dodge, K. A. (1992). Social information processing in aggressive and depressed children. Child Development, 63, 1305-1320.

Rose, A. J., \& Asher, S. R. (1999). Children's goals and strategies in response to conflicts within a friendship. Developmental Psychology, 35, 69-79.

Rose, A. J., \& Asher, S. R. (2004). Children's strategies and goals in response to help-giving and help-seeking tasks within a friendship. Child Development, 75, 749-763.

Rose, A. J., \& Rudolph, K. D. (2006). A review of sex differences in peer relationship processes: Potential trade-offs for the emotional and behavioral development of boys and girls. Psychological Bulletin, 132, 98-131.

Rudolph, K. D., Hammen, C., \& Burge, D. (1994). Interpersonal functioning and depressive symptoms in childhood: Addressing the issues of specificity and comorbidity. Journal of Abnormal Child Psychology, 22, 355-371.

Rudolph, K. D., Hammen, C., Burge, D., Lindberg, N., Herzberg, D., \& Daley, S. E. (2000). Toward an interpersonal life-stress model of depression: The developmental context of stress generation. Development and Psychopathology, 12, 215-234.

Schwab-Stone, M. E., Ayers, T. S., Kasprow, W., Voyce, C., Barone, C., Shriver, T., \& Weissberg, R. P. (1995). No safe haven: A study of violence exposure in an urban community. Journal of the American Academy of Child and Adolescent Psychiatry, 10, 1343-1352.

Spence, S. H., Donovan, C., \& Brechman-Toussaint, M. (1999). Social skills, social outcomes, and cognitive features of childhood social phobia. Journal of Abnormal Psychology, 102, 211-221.

Spence, S. H., \& Liddle, B. (1990). Self-report measures of social competence for children: An evaluation of the Matson Evaluation of Social Skills for Youngsters and the List of Social Situation Problems. Behavioral Assessment, 12, 317-336.

Suveg, C., \& Zeman, J. (2004). Emotion regulation in children with anxiety disorders. Journal of Clinical Child and Adolescent Psychology, 33, 750-759.

Tolan, P. H., Gorman-Smith, D., Huesmann, L. R., \& Zelli, A. (1997). Assessing family process to explain risk for antisocial behavior and depression among urban youth. Psychological Assessment, 9, 212223.

Underwood, M. K., Hurley, J. C., Johanson, C. A., \& Mosley, J. E. (1999). An experimental, observational investigation of children's responses to peer provocation: Developmental and gender differences in middle childhood. Child Development, 70, 1428-1446.

Waasdorp, T. E., Bagdi, A., \& Bradshaw, C. P. (2010). Peer victimization among urban, predominantly African-American youth: Coping with relational aggression between friends. Journal of School Violence, 9 , 98-116.

Wichmann, C., Coplan, R. J., \& Daniels, T. (2004). The social cognitions of socially withdrawn children. Social Development, 13, 377-392. 
Wright, J. C., Zakriski, A. L., \& Drinkwater, M. (1999). Developmental psychopathology and the reciprocal patterning of behavior and environment: Distinctive situational and behavioral signatures of internalizing, externalizing, and mixedsyndrome children. Journal of Consulting and Clinical Psychology, 67, 95-107.
Xue, Y., Leventhal, T., Brooks-Gunn, J., \& Earls, F. J. (2005). Neighborhood residence and mental health problems of 5- to 11year-olds. Archives of General Psychiatry, 62, 554-563.

Zeman, J., Shipman, K., \& Suveg, C. (2002). Anger and sadness regulation: Predictions to internalizing and externalizing symptoms in children. Journal of Clinical Child and Adolescent Psychology, 31, 393-398. 